\title{
Aristóteles e a práxis: uma filosofia do movimento
}

\author{
Aristotle and praxis: a philosophy of movement \\ Aristóteles y praxis: una filosofía del movimiento \\ LÍlian DE ARAGÃo BASTOS DO VALLE*
}

\begin{abstract}
RESUMO - Muito embora a notável influência que continua inegavelmente a exercer no campo filosófico, a obra aristotélica permanece, no que respeita à reflexão correntemente praticada no campo educacional, quase inexplorada. Buscando desfazer alguns preconceitos e desautorizar lugares-comuns que, baseados em leituras pouco confiáveis do autor, não encontram fundamento nos textos, este artigo examina como se tematiza e equaciona, em algumas de suas obras, a relação entre vida e movimento. E, muito especialmente, o movimento humano, cerne da reflexão e da prática educacionais: movimento, pois, como atividade de formação, como capacidade de autoformação e, mais amplamente, como práxis.
\end{abstract}

Palavras-chave - Aristóteles. Movimento. Autoformação. Ação. Práxis.

\begin{abstract}
Although the remarkable influence still exerted on contemporary philosophy, Aristotle's work remains virtually unexplored by educational field. Seeking to dispel some prejudices and commonplaces based on unreliable readings, this article examines how the author thematizes, in some of his works, the relationship between life and movement. And, especially, human movement, core of educational thought and practice: movement as activity of human formation, as a capacity of self-formation and, more broadly, as praxis.
\end{abstract}

Keywords - Aristotle. Movement. Self-formation. Action. Praxis.

RESUMEN - Más allá de la notable influencia que innegablemente continua a ejercer en el campo filosófico, la obra aristotélica, colocada en relación con la reflexión usualmente aplicada en el campo educativo, permanece casi inexplorada. Tratando de disipar prejuicios y lugares comunes que, basados en lecturas poco fiables del autor, no encuentran ningún fundamento en el texto aristotélico, este artículo examina como se tematiza y se analiza en algunas de sus obras, la relación entre la vida y el movimiento y, muy especialmente, el movimiento humano, como centro de la reflexión y de la práctica educativa: el movimiento como actividad de formación, como capacidad de autoformación y, más ampliamente, como praxis.

Palabras clave - Aristóteles. Movimiento. Autoformación. Acción. Praxis.

Heráclito afirma que tudo é movimento, que nada subsiste; $e$, comparando as coisas deste mundo ao curso de um rio: duas vezes em um mesmo rio não poderás jamais mergulhar.

PLATÃo, Crátilo, 402a

"Ainda que Aristóteles seja tido, desde a Idade Média, por 'mestre dos que sabem', a história da educação não viu nele o mestre daqueles que aprendem, e ainda menos daqueles que ensinam": com essas palavras, Jean Lombard (1994) introduz seu livro de divulgação sobre as relações entre a obra aristotélica e a educação - um dos tantos que o autor dedicou a influentes filósofos. Como esse, outros trabalhos, mais ou menos recentemente, buscaram apresentar uma visão geral das contribuições do pensamento de Aristóteles para a educação. Isso, porém, pouco altera o quadro de histórico desinteresse pelo que Charles Hummel (1998, p. 138) nomeou "Aristóteles educador", cujas supostas razões coubera ao ponderado H.-I. Marrou (1948, p. 210) sintetizar: a obra pedagógica de Aristóteles, comenta o historiador após um longo estudo das concepções platônicas, não apresentaria "o mesmo caráter de originalidade criativa que a de Platão ou Isócrates".

\footnotetext{
* Doutora em Educação pela Universidade René Descartes - Paris V (Paris, França) e Professora na Universidade do Estado do Rio de Janeiro (Rio de Janeiro, RJ, Brasil).E-mail:<lilidovalle@gmail.com>.
} 
Seria decerto um exagero falar em "obra pedagógica" de Aristóteles; tampouco deixou o autor um modelo educacional em ruptura com a tradição democrática. Longe disso, o filósofo só fez destacar a importância da paideia na constituição da polis (como, por exemplo, no livro VIII da Política) e na formação humana (como no livro X da Ética a Nicômaco).

Entretanto, queremos acreditar que a atualidade que se deve reivindicar para a obra aristotélica, no que respeita à educação, situa-se menos nessas passagens em que a formação humana é explicitamente tematizada do que no formidável arsenal de conceitos e de reflexões antropológicas por esta obra legado, que permitem repensar mais profundamente nossas concepções e nossas práticas educativas ali mesmo onde, ao invés de abrirem-se a novas interrogações, elas parecem se assentar sobre noções e representações inquestionadas.

Nesse sentido, arriscando-nos a decepcionar aqueles que buscam "conclusões" fechadas, o objetivo do presente texto é menos o de conduzir a novas certezas do que sugerir certos caminhos de reflexão que o pensamento de Aristóteles nos abre. Renunciando aos comentários de caráter geral sobre a obra de Aristóteles, buscaremos examinar, com o apoio de reconhecidos especialistas, apenas alguns conceitos que nos parecem servir de instrumentos afiados para pensar aquilo pelo que pretendemos definir o humano: o movimento e, muito particularmente, a iniciativa - a ação.

\section{O HUMANO: MOVIMENTO COMO INICIATIVA}

Uma parte significativa do esforço racional que constitui o legado da Antiguidade definiu-se pela exigência de conferir sentido à experiência de um mundo que só se deixa apreender como pura instabilidade: é nesta tradição, para a qual a tarefa primordial da filosofia é "preservar a unidade da dispersão movente e ilimitada do múltiplo" (MOREL, 2003, p. 7-8), que se deve primeiramente situar o pensamento de Aristóteles. Mas é também no seio desta tradição que a originalidade da contribuição aristotélica pode ser convenientemente aquilatada, pelo tratamento que o filósofo forneceu para esta árdua questão. E isso porque, em contraste com Platão - que, recusando obstinadamente qualquer inteligibilidade para as coisas corruptíveis, afirmara a impossibilidade de uma "ciência do devir", isto é, de uma física,

[...] a atitude de Aristóteles [...] consiste, a maior parte do tempo, em se submeter diretamente à prova do múltiplo, recusando-se a reduzi-lo ali onde é impossível fazê-lo, buscando organizá-lo e não superá-lo (MOREL, 2003, p. 106).
Não por acaso, os dois domínios que resistem mais fortemente à formalização racional são exatamente aqueles aos quais Aristóteles consagrará a maior parte de sua obra: a natureza, em geral e, de forma muito particular, o humano.

A vida, como quer que ela se manifeste - espécies animais, funções orgânicas, atividades cognitivas, virtudes, concepções de felicidade e de regimes políticos - revela a grande exuberância do real, a desafiar a capacidade humana organizadora. Por essa razão, o problema do ser e da existência é crucial. Mas isso não significa, como equivocadamente se propôs, que a obra aristotélica possa ser limitada à filosofia natural, tanto quanto não autoriza a imaginar que as posições do autor caracterizem um irresoluto "empirismo": longe de lá, o estudo das coisas humanas marca de uma ponta a outra a reflexão aristotélica, forçando-a a uma complexidade e sutileza que, presentes já em sua análise do vivente em geral, ganham aí toda sua amplitude.

Mas é claro que, para Aristóteles, o ser é, primeiramente, natureza - phýsis. Ora, a natureza é impulso endógeno, crescimento espontâneo - em uma palavra, movimento. No livro II da Física aristotélica, os seres naturais são apresentados (por oposição aos seres artificiais, para os quais o movimento só ocorre por acidente, causado por um agente exterior que age sobre sua matéria) como comportando neles próprios a causa de seu movimento e repouso (ARISTÓTELES, Física, II, 192 b 8). ${ }^{1}$ Esta causa é imanente, e age diretamente, isto é, sem intermediários: a natureza é, pois, apresentada como princípio interno de cada vivente. Por isso, a filosofia natural de Aristóteles examina o vivente como aquele que é capaz de metabolè, de mudança, em qualquer das acepções em que ela ocorre: como movimento local, como mero deslocamento (phorá), como ciclo incoercível de crescimento (aúxesis) e declínio (phthísis), de geração (génesis) e de corrupção (phthorá); ou como modificação quantitativa (alloiosis). (Id., passim).

Ainda que recusando a proposta de imobilidade formulada pela tradição eleata - cujo principal nome é Parmênides - e também a de um princípio único e móvel, como a água (Tales) e o ar (Anaximandro), Aristóteles retira do minucioso estudo de seus predecessores (além dos mencionados, Empédocles, Demócrito, Anaxágoras), a noção em toda parte dominante dos princípios contrários, de que fará a base de sua posição: não é possível pensar o ser sem sua contrariedade. A vida se entende, pois, pela oposição entre determinação, que Aristóteles denomina ê̂dos, forma, e ausência de determinação, a stéresis (Id., I, 190 b 27; II, 192 a 27). Mas isto decerto não seria suficiente para pensar o ser e o movimento; é preciso que haja ainda um terceiro termo, "que permita compreender, ao mesmo tempo, a permanência relativa daquilo que 
devém e a forma de correlação dos contrários" (MOREL, 2003, p. 32): esse terceiro termo é, para Aristóteles, a matéria. A matéria é substrato, indeterminação relativa, potência de determinação.

Para Platão, o paradigma do ser era a determinidade: e a plenitude de determinação só podia ser pensada como imobilidade. Assim sendo, como Castoriadis não cessava de destacar, passou à tradição filosófica a desconfiança em relação à ação, ao movimento:

É uma pista luminosa, embora talvez unilateral, pensar a história da filosofia em sua vertente central como a elaboração da Razão, homóloga à postulação do ser como ser determinado, ou seja, a determinidade (péras, Bestimmtheit). [...] o que não decorre da Razão e do Ser determinado foi sempre adscrito, nessa vertente central, ao infrapensável ou ao suprapensável, à indeterminação como simples privação, déficit de determinação, isso é, de ser, ou a uma origem absolutamente transcendente e inacessível a toda determinação (CASTORIADIS, 1987, p. 335).

De uma certa forma, a ontologia aristotélica não foge à regra, na medida em que considera o ser da perspectiva de sua realização plena (enérgeia) - o que foi exaustivamente observado pela crítica. Contudo, muito menos atenção se deu ao fato de que esta mesma ontologia abre uma nova possibilidade, ao propor que à noção de determinação plena possa também corresponder uma atividade, como é, por exemplo, o caso da theoría (ARISTÓTELES, Física, Q, 1048 a 32-35). Assim sendo, e contrariamente a análises mais apressadas, a introdução da oposição entre potência (dýnamis) e ato (enérgeia) está longe de marcar necessariamente uma redução do ser à imobilidade e à tautologia (MOREL, 2003, p. 124): e é este espaço que se abre para a reflexão sobre a singularidade da ação (e da formação) humana.

Pois, no caso específico do humano, o ser já não pode ser pensado apenas sob o modo do movimento "natural" ele que se define também como capacidade de iniciativa, como poder de autoalteração que leva sempre além do que a natureza dispõe:

[...] buscando a felicidade, nós buscamos o bem propriamente humano, isto é, aquilo que, no homem, é natural ao homem; mas nós só podemos atingi-lo por meios que estão unicamente sob a iniciativa humana, como a educação, as leis, a prática da virtude ou a boa deliberação. O homem é, assim, um animal paradoxal, cuja natureza é de superar sua própria natureza. Seria, pois, vão querer a todo preço "naturalizar" a filosofia prática [de Aristóteles], reduzindo as ações humanas a comportamentos mais ou menos conformes a uma suposta norma natural; mas seria igualmente ilusório pretender isolar as determinações puramente humanas de toda referência à natureza e à causalidade física (MOREL, 2003, p. 10).
A especificidade do movimento humano põe à prova a ontologia aristotélica e a leva às últimas consequências: no intrincado jogo de conceitos e definições que, a partir daí, servem para pensar a ação - e, por isso mesmo, as formas singulares pelas quais o humano se apresenta -, repousa, a nosso ver, parte substancial da contribuição de Aristóteles para a reflexão sobre a formação humana na atualidade.

\section{PRESENÇA COMO AÇÃo}

São duas as qualidades pelas quais os seres dotados de psiquê (émpsykon) parecem diferir radicalmente daqueles que não o são (apsýkon):

o movimento e o fato de sentir. Nós aceitamos estas duas características de distinção da psique de nossos predecessores. ARISTÓTELES, De Anima, I, 2, 25

Como definir a presença? Para tudo que existe, a presença é o fato de simplesmente "estar aí". Há, porém, um tipo especial de vivente, que os gregos diziam émpsykon, isto é, dotado de psique, para quem a presença, como Aristóteles assinala no início do tratado que dedicou à questão (cf. ARISTÓTELES, De Anima, I, 1, 408 b 25), também se define e se realiza como movimento (Id., 403 b 25-27; 405 b 11). E, não obstante os sentidos que a cultura cristã pôde acrescentar à psique, então vertida no latim anima, é nesta acepção que até hoje, na maioria das vezes, nos referimos ao ser animado. No entanto, os gregos iam mais longe: eles sublinhavam que é da natureza dos animais ter o princípio deste movimento em si próprios: neles, o movimento não é causado por nenhum agente exterior, senão que se origina no ser. Neste sentido, o animal é, etimologicamente, o verdadeiro autômato, que se movimenta por si mesmo. Este movimento natural, que, vê-se logo, é muito mais do que mero deslocamento, nada tem entretanto de errático e fortuito: ele conduz, diz Aristóteles, o ser em direção a seu destino, a seu acabamento (restando-nos, é claro, a tarefa de pensar no agente e produtor deste destino...) (Cf. ARISTÓTELES, De Anima, 412 a 20).

Além disso, o ser animado também se apresenta, segundo a tradição grega, como capacidade de sentir, de se deixar afetar por aquilo que ele não é: o movimento natural abre, assim, no espectro da existência, um amplo painel de experiências que vão desde a simples reação mecânica de evitação ou atração até a capacidade de "adquirir aquilo que não se tem" (PLATÃO, Mênon, 70 a) - em uma palavra, de aprender e de se adaptar e, acessoriamente, de conhecer e de criar. De forma mais geral, pode-se porém dizer que, enquanto o movimento próprio distingue o vivente de todo o resto das coisas que 
existem, a capacidade de se deixar afetar, a possibilidade de sofrer uma mudança imposta por um agente externo, é, ao contrário, partilhada com todos os seres inanimados... ${ }^{2}$ Assim, a dupla característica, movimento e sensibilidade, cedo se apresentou sob a forma de clivagens a que até hoje se recorre para explicar os modos de presença do humano: enraizou-se aí a oposição entre soma e psique, tanto quanto entre passividade e atividade.

Ora, para a educação, a crítica a estas oposições é fundamental, na medida em que elas determinam os limites de nosso entendimento acerca daquilo a que visa, essencialmente, o movimento da formação humana: o impulso endógeno, e não a pura receptividade, autoalteração e não simplesmente a reação passiva à ação externa - em uma palavra, autônoma criação do que aqui designamos por "modos de presença e de ação" próprios a cada ser.

Ao se falar em criação autônoma, decerto não se está sugerindo que a autoalteração do humano émpsykon se dê sem a participação da alteridade (seja ela a figura de um outro émpsykon ou, simplesmente, este correlato somático da psique que é o corpo), sem a influência do meio social. Mas este é, afinal, o nó da questão a desatar, em que se enredam (falsas) oposições como individualidade e sociedade, singularidade e alteridade, interioridade e exterioridade, presença e distância, materialidade e sentido, passividade e atividade...

Uma longa tradição filosófica que vai da Antiguidade até os tempos modernos sustentou que, em contraposição à "atividade", movimento autêntico da psique, o corpo, matéria, seria aquilo que se deixa passivamente afetar. Sujeito a todo tipo de influências, o corpo deveria ser, portanto, objeto de controle permanente, de forma que, por via da sensação, sobre ele não se exercessem as forças capazes de vir a corromper o espírito. Assim, a educação buscou tradicionalmente dominar sobre os corpos para moldar, como os estudos de Foucault bem mostraram, a atividade das almas (FOUCAULT, 1978; 2005). No entanto, a simples hipótese de que se possa de fato "modelar" as almas demonstra bem como, afinal, foi a representação do humano como um todo que esteve contaminada pelo sentido passivo que tem no corpo a melhor metáfora.

Na modernidade, a negação da "substancialidade" da alma conduziu à sobrevalorização da atividade, entendida pelo empirismo em seu sentido mais genérico e mecânico, para enfim resultar, mais ultimamente, em um enorme impasse para a educação - quando algumas formulações pretendidamente "pós-modernas", radicalizando concepções mais sutis de alguns filósofos, passam a sugerir que o humano é "fluxo" que jamais se fixa no que Aristóteles denomina de "forma" - num modo de estar presente e de agir.
Mas é claro que a simples eliminação da palavra forma não resolve o problema introduzido pela noção de uma fôrma que, dada pela natureza, guiaria prévia e cegamente o movimento humano a seu destino geral e inexorável, fazendo da iniciativa e da singularidade humanas meras ilusões. Ocorre que esta visão não encontra, no texto aristotélico, o apoio e a justificação que muitas vezes se imaginou. $\mathrm{Na}$ antropologia aristotélica, de fato a matéria (o corpo) é princípio de indeterminação, potência (dýnamis), enquanto a forma (a alma) é determinação e, neste sentido, realização (entelécheia). Isso não quer dizer que, sobretudo no humano, a alteração introduzida pelo movimento naquilo que se é ou na maneira como se age seja necessariamente predefinida, tanto quanto absoluta ou permanente (MOREL, 2003, p. 133). E é aqui que a análise do texto aristotélico ganha toda sua importância.

\section{ENTELÉQUIAS: O MOVIMENTO COMO INSTITUIÇÃO/REALIZAÇÃO DOS MODOS DE SER}

Movimento: concebido como deslocamento físico, ele se estabelece como o que está entre um ponto de partida e um ponto de chegada - entre, se quisermos, uma "origem" e um "destino". Mas o movimento também é o que conduz de um "antes" a um "depois": neste caso, ele se refere, mais também do que à presença física, àquilo que constitui o ser.

No Tratado sobre a alma (De Anima), o movimento é, como já mencionamos, a própria natureza do ser animado, é atividade (enteléquia) em direção à sua realização (a seu télos) (ARISTÓTELES, DA, 412 a 20). Mas esta ampla definição de que parte Aristóteles vai aos poucos dando lugar a importantes precisões, como a que distingue o movimento que tem origem no próprio sujeito e aquele que depende de um agente exterior; e a que separa uma efetiva alteração do ser, passagem ao dessemelhante, e a mera reiteração, ou o acabamento do mesmo.

É nesta última acepção que usualmente se imagina que a reflexão de Aristóteles se move e se contém; no entanto, o texto aqui examinado deixa claro que não há apenas uma forma de se entender a relação entre potência e ato, ou realização (Id., 417 a 20).

Pode-se dizer, por exemplo, propõe o De Anima (417 b 23-25), que um indivíduo é sábio porque ele pertence a uma espécie de seres capazes de possuir a ciência; mas, em outro sentido, diz-se que é sábio o caso específico do sujeito que adquiriu uma "certa" ciência. A estas duas acepções diferentes da noção de "potência" correspondem diferentes tipos de movimento, de realização, ou de atuação: um deles leva da aptidão geral de conhecer que é dada a todo humano à aquisição de uma 
ciência particular, ${ }^{3}$ promovida pela aprendizagem; o outro indica a passagem da posse ao exercício efetivo do saber. Num caso, há passagem de uma possibilidade ainda indeterminada à aquisição de uma capacidade específica - realização do ser como tendo em si, a partir daí, esta aptidão: há, assim, alteração qualitativa do que se é. No outro caso, quando há ativação de uma potencialidade já adquirida, ocorre a "conservação do ser em potência pelo ser em ato" (Id., ibid.), sem qualquer aquisição ou mudança qualitativa.

O outro caso apresentado por Aristóteles refere-se à sensação (Id., 417 a 5-15): aqui também é possível distinguir a sensação como possibilidade genérica, ou simples posse da capacidade sensitiva, da sensação em ato. Mas o paralelo se extinguiria aí: pois a posse da sensibilidade, tanto quanto o ato da sensação, parecem depender inexoravelmente de um agente externo - do progenitor de quem o ser sensível recebe esta capacidade e dos objetos que se apresentam a cada vez ao sujeito.

Para o ser sensível, a primeira mudança se produz sob a ação do progenitor: uma vez engendrado, ele possui a sensação [...] $\mathrm{Na}$ sensação em ato... os agentes produtores do ato são exteriores: são, por exemplo, o visível e o sonoro, assim como todos os outros sensíveis (ARISTÓTELES, DA, 417 b 17-25).

Dessa forma, não há uma perfeita simetria entre a aptidão de sentir e a aptidão de conhecer, tanto quanto entre a sensação em ato e o exercício da ciência, já que, registra Aristóteles, no que concerne à ciência, está no sujeito e apenas nele a origem do movimento que conduz à realização do ser - seja esta realização entendida como aquisição de disposições ou aptidões outras, seja a efetivação e reafirmação do modo de ser previamente determinado (Id., 417 b 16). Entretanto,

O primeiro nível de realização - a posse da ciência - ou 'realização primeira' (entelécheia prôtê) é ainda uma atividade potencial, enquanto a segunda corresponde à atividade como tal (MOREL, 2003, p. 137).

Dessa maneira, Aristóteles distingue, no humano, a posse de disposições estáveis, ou de potencialidades bem determinadas (as quais ele denomina de "potências de segundo nível") tanto do exercício efetivo destas disposições (a "enteléquia segunda") quanto de sua aquisição, e da aquisição potencial ("enteléquia primeira") de novas disposições (de novas hexeis). Foi exatamente a esta possibilidade que Castoriadis denominou de "poder-poder ser" - a pura potencialidade que é própria da autocriação humana. Dever-se-ia, então, reservar para a noção de formação humana o sentido instituinte que se pode antever na entelécheia prôtê, entendendo a enteléquia segunda como mera consequência, ou aplicação, das aquisições que definem o ser?

Os desenvolvimentos consagrados por Aristóteles ao exercício ou à ativação de capacidades que o humano tem potencialmente nos previnem contra esta decisão, ao mesmo tempo que desautorizam a associação de sua filosofia a uma representação rígida da subjetividade, inteira e previamente determinada pelas potencialidades definidas na natureza. O ser, diz-nos ele, é atividade primeira - nele encontra-se permanentemente ativo um conjunto aberto de disposições ou potencialidades, a serem elas próprias ativadas: "[...] a psique é a realização primeira (enteléquia proté) de um corpo natural que possui a vida em potência" (412 a 27 b 1).

A vida é atualização (entelécheia) nos dois sentidos do termo: a posse da sabedoria, que corresponde já a um nível de atividade, é necessária, mas não realiza o sábio apenas o exercício da sabedoria pode fazê-lo inteiramente. Na Ética a Nicômaco, isto é ainda mais evidente: a virtude, diz então Aristóteles, para referir-se ao que chamaríamos hoje de "ética", não é uma afecção (páthos) nem uma potência (dýnamis), mas uma disposição para a deliberação (héxis proairetikê) (ARISTÓTELES, Ética a Nicômaco, II, 1105 b 20 - 1106 a 15), um habitus, o modo de ser de quem se interroga sobre a justiça:

\footnotetext{
'A virtude é uma disposição adquirida (héxis) deliberativa... definida pelo lógos e como a definiria o phónimos.' A héxis é uma disposição que não é 'pura', nem "espontânea": ela é, e deve ser, adquirida (por isso o papel decisivo da paideia e do nomos). Ela é proairétiké, em dois sentidos: no sentido de seu 'objeto', transitivamente, ela concerne à escolha, ela é um habitus que leva a escolher bem. Mas ela é também proairétiké, deliberativa, porque é um habitus de deliberação (reflexivo e deliberativo!), ela não é simples habitus, automatismo mecânico, ela guarda a proaíresis, a intenção e a escolha. Ela é definida pelo lógos - contém, portanto, um elemento racional e discutível. Mas ela não é nem mecanizável nem simplesmente universalizável: ela é tal como a definirá o phónimos, aquele que possui a phrónesis (CASTORIADIS, 2000, p. 56).
}

Não é apenas, portanto, a concepção substancialista que encontra aqui alternativa conceitual: é também a própria oposição entre potência e ato, entre substância e movimento que se vê ameaçada, na medida em que a ênfase na atividade abre caminho para se entender, também, a passagem de uma enteléquia à outra. Ao invés de termos extremos, tem-se agora um caminho de mão dupla, pelo qual passa-se da posse de uma característica à sua ativação, mas também da atividade a uma nova aquisição. Afirmando disposições e aptidões dispostas 
pela natureza, Aristóteles considera as condições de sua ativação, mas também o fato de que estas disposições podem ser, elas próprias, adquiridas; e é por esta via que o indivíduo da espécie se singulariza e constitui, afinal, o seu modo de ser próprio (habitus) - com as características que são a cada vez as suas:

[...] a héxis não permite apenas ao ato de se repetir e, assim, de se exercer de novo graças às virtudes formadoras bem conhecidas do hábito, mas, polarizando-o ativamente, ela o conduz a exercer melhor, assim como ela o conduz, também, por outro lado, a realizar concomitantemente o acabamento de seu objeto segundo uma típica dominante (RODRIGO, 2006, p. 119).

Sobre isso, Aristóteles é muito claro: a atividade repetida não apenas leva ao aperfeiçoamento, mas faz o caminho de volta até a potência, cria novas potencialidades.

Todas estas considerações seriam todavia banais, se as noções de exercício e de repetição não tivessem sido, há algum tempo, exiladas da reflexão e da prática educacionais, em virtude da suspeita de que de fato nada acrescentam à formação, além da reiteração mecânica e alienada de gestos desprovidos de sentido. Deste modo, reintroduzindo a questão abandonada, esta dinâmica das duas enteléquias indica, na grande amplitude conferida ao sentido do movimento propriamente humano, a forma geral pela qual se dá a passagem do mesmo ao outro, pela qual advém a alteração; na prática, torna-se difícil distinguir as fronteiras entre atividade e potência, entre aquisição e realização:

Os dois... são [...] "sábios" em potencial. Mas, enquanto um "atualiza sua potência" após tornar-se outro pela aprendizagem e ter seguidamente passado de um estado a seu oposto, o outro "atualiza sua potência, passando", diferentemente, da simples posse [...], sem o exercício, a seu exercício. [...] (ARISTÓTELES, DA, II, 417 a $30-417$ b 5).

Há, pois, sem dúvida, terreno aberto para retrucar aos nossos hábitos mentais solidamente estabelecidos e, em particular, aos herdeiros do escolanovismo exacerbado, que a metódica substituição do exercício e da repetição pela "espontaneidade", pelo ato singular que jamais volta, longe de garantir a instituição do novo, pode mascará-lo, mergulhando-o na indistinção do errático, no descompromissado, no fortuito, no superficial... Neste ponto, a lição (lógica) dos antigos é de puro bom senso: não há, ao menos para os humanos, alteridade sem identificação, ruptura sem permanência, contrariedade sem semelhança; não há movimento sem repouso, não há figura sem fundo... O gesto singular se destaca porque tem como cenário a repetição do gesto: e se aos humanos é dado recomeçar a cada vez como se cada gesto fosse o primeiro e o único (DELEUZE, 1989, p. 58), como esquecer que isto também significa que apenas a eles acontece de "[...] mover-se ao longo de uma linha reta num universo em que tudo o que se move o faz num sentido cíclico" (ARENDT, 1987, p. 27)?

\section{HéXis e Diathésis: o Movimento COMO (AUTO)POÍESIS}

assim, para a educação, a afirmação da presença como manifestação das diversas dimensões do movimento de realização do ser implica todo um programa de trabalho, que vai do questionamento das representações mais corriqueiras do aluno - nas quais a imobilidade não é decisão teórica, mas resultado de múltiplas reduções antropológicas - até a investigação de novos horizontes conceituais que, obrigando a algum distanciamento crítico, nos permitam repensar nossas práticas educativas ali onde elas se mostram em claro descompasso com as exigências e características da sociedade.

É o caso, tornado mais do que atual pela rápida expansão da modalidade de educação on-line, da oposição entre atividade e passividade, ou entre agente e paciente.

Mencionamos anteriormente que as raízes intelectuais desta oposição podem ser localizadas na separação corpo e alma empreendida pela tradição ocidental, tanto quanto no crescente desprestígio a que passaram a estar submetidas, no apogeu da modernidade, a dimensões humanas associadas à corporeidade e à sensação.

Ainda aqui, não se encontrarão em Aristóteles os argumentos para tal empreitada. Pelo contrário: em sua concepção, muito longe de se oporem, matéria (hýle) e forma (morphé) existem como um todo indecomponível - não só a psique se deixa afetar por fenômenos puramente fisiológicos, como o corpo é constantemente in-formado pelo que, no humano, supera largamente a pura materialidade. Por isso mesmo, em Aristóteles, como observa Pierre-Marie Morel, a alma - a psique - está longe de ser "o princípio determinante de um corpo que, sem ela, seria absolutamente indeterminado" (MOREL, 2003, p. 139).

No entanto, vimos de observar que o De Anima sustenta uma clara diferença entre a sensação - que, tanto em ato como em potência, dependeria de um agente externo - e a cognição - que, como potencialidade ou como atividade, realizar-se-ia sempre por via da iniciativa do sujeito: não estaria aí a prova de que, de fato, Aristóteles reservara para a sensibilidade o caráter passivo que cuidadosamente rejeitava para a cognição?

Esta é, sem dúvida, a concepção mais do que dominante na história da filosofia, onde, como bem lembrava Castoriadis, vigorou por muito tempo um "privilégio 
ontológico exorbitante atribuído à res (extensa e cogitans, uma indissociável da outra)" que mal encobria "a contínua subordinação da filosofia às exigências da instituição social-histórica [...]" (CASTORIADIS, 1982, p. 376).

A questão é complexa: afinal, não é possível negar que, tomada como tal, a sensação não se produz senão como efeito de um agente externo sobre o ser sensível, que deve ser, pois, considerado como paciente. Mas o que, de fato, o objeto sensível determina? Sem dúvida não é a própria sensibilidade, que é sempre muito mais do que uma simples reação a um estímulo físico; além disto, como o que toca o órgão sensorial não é jamais o objeto material ele próprio (Aristóteles, DA, III, $431 \mathrm{~b}$ 20-25), é preciso admitir que há, por parte do ser sensível, atividade, e não apenas recepção passiva:

A sensação se caracteriza assim por uma aptidão imediata à abstração (aphaíresis), isto é, por uma capacidade para discernir propriedades sem ter necessidade de absorver fisicamente seu substrato material. É esta abstração espontânea da sensação que permite a constituição da imagem (phantasma) e a apreensão dos inteligíveis (noèta) (MOREL, 2003, p. 144$){ }^{4}$

No humano, a sensação envolve, portanto, uma atividade que P.-M. Morel denomina "paradoxal", já que leva do objeto material à mudança física do órgão sensorial sem que haja, entre eles, o que caracteriza o fenômeno material: o contato. Além disso, embora os sentidos de que o humano é dotado sejam diferentes e captem diferentes aspectos de um mesmo objeto, há uma síntese que se realiza - que Aristóteles atribuía a um sentido comum (próprio (Aristóteles, DA, III, 1, 424 b 20-427 a 14).

Mas ficam sobretudo evidentes, no exame da sensibilidade, as implicações da concepção hileformista: recusando-se a separar corpo e alma, sensível e cognoscível, Aristóteles não admite a divisão da alma em "faculdades" estanques, os poderes ou potências "se realizam diferentemente mas só existem efetivamente como um" (CASTORIADIS, 1987, p. 344), e por via da atividade da imaginação:

[...] corpo e alma não são componentes entremeados, nem "coisas" que se fundiriam uma na outra, mas dois aspectos complementares ou os dois níveis funcionais da atividade do vivente. [...] A questão da unidade resiste, no entanto, pois poderíamos ser tentados, sobretudo por influência de Platão, a distinguir as partes da alma, por exemplo uma parte racional e uma parte desejante. O problema da unidade do vivente é, pois, menos o da alma e do corpo do que das diferentes faculdades ou potências (dunameis) da alma (MOREL, 2003, p. 139-140). ${ }^{5}$
Porém, do paradigma hilemorfista à definitiva dominação do modelo de separação radical entre sujeito e objeto da ciência, tal como a modernidade a formulou, vão-se, de fato, muitos séculos, ao longo dos quais preparou-se, por via da divisão entre corpo e alma, a paulatina perda da referência à materialidade e o consequente esvaziamento da presença que passaram a constituir a experiência contemporânea do conhecimento (GUMBRECHT, 2010, p. 42). Hans Gumbrecht localiza na teologia e no teatro medievais os sinais precursores do fenômeno que, de Descartes e a dominância do cogito até o ideal de conhecimento erigido pela modernidade, exilará cada vez mais o corpo humano na exterioridade muda do mundo de coisas. Dá-se, porém, com Kant a culminância (e igualmente o início da decadência) deste processo, no qual a consciência da distância entre sujeito e mundo é levada a seu extremo (Id., p. 59).

Ao buscar estabelecer a primazia do entendimento, Kant oporá a "receptividade das impressões" à "espontaneidade dos conceitos", estabelecendo solidamente não apenas a imagem do observador incorpóreo, mas igualmente a ilusão de estabilidade das referências sobre as quais o entendimento se assenta. É claro que, neste contexto, só resta à sensibilidade a experiência - se é que assim se pode dizer - da pura "receptividade". "Mas o que é, de fato, essa receptividade de impressões?", pergunta-se Castoriadis.

De fato, não há nenhuma 'receptividade' ou 'passividade' das 'impressões'. Para começar, não há 'impressões'. As 'impressões' são um artefato filosófico ou psicológico. Há, em alguns casos, percepções a saber, representações correlativas a objetos 'externos' e mais ou menos 'independentes'. [...] Essas percepções comportam, sem dúvida, um componente 'sensorial'. Mas esse componente é, ele próprio, uma criação da imaginação. Os 'sentidos' fazem emergir, a partir de um X, algo que 'fisicamente' ou 'realmente' não existe - se entendemos por 'realidade' a 'realidade' da física: eles fazem emergir as cores, os sons, os odores, etc. Na natureza 'física' não há cores, sons e odores: há somente ondas eletromagnéticas, vibrações do ar, espécies de moléculas, etc. O quale sensível, as famosas 'qualidades secundárias' são uma pura criação da sensibilidade, isso é, da imaginação em sua manifestação mais elementar, dando uma forma, e uma forma específica, a algo que, 'em si', não tem nenhuma relação com essa forma (CASTORIADIS, 1999, p. 272). ${ }^{6}$

A tradição filosófica identificava nos objetos a origem das "qualidades secundárias" apreendidas pela percepção. Mas estas são, comenta Castoriadis, pura criação da imaginação humana, que fornece "uma forma, e uma forma específica, a algo que, "em si", não tem nenhuma relação com essa forma". (Id., ibid.). 
À sensibilidade corresponde, portanto, uma atividade específica, que consiste, por um lado, na promoção, pela abstração e pela síntese, da matéria em objeto sensível; e, por outro, em uma alteração que, no humano, realiza-se com apoio dos órgãos sensoriais, mas vai sempre muito além daí.

A sensação é, assim, atividade em diferentes sentidos do termo. Em De Anima (II, 5, 417 b 15-25) Aristóteles distingue a sensação como enteléquia primeira, passagem da aptidão geral da espécie à sensibilidade própria do indivíduo, pela aquisição de um modo de ser, de uma héxis; e, em seguida, passagem desta atividade ainda potencial à enérgeia, que coincide aqui com a enteléquia segunda, a sensação em ato.

Há já nesta primeira passagem, como vimos, participação ativa da imaginação - que, neste nível, não distingue o humano do restante dos animais. Contudo, não bastaria, para ir adiante, comparar os equipamentos sensoriais diferentes que fazem com que, mesmo se "os insetos veem cores" (CASTORIDAIS, 1999, p. 97), o que veem não é o mesmo que vemos; é preciso admitir que, ao lado desta primeira realização (enteléquia) da base natural, na forma de uma sensibilidade "anônima", realizase também, concomitantemente, no caso do humano, uma aquisição que permite que se fale de determinação individual: um modo de ser de sua sensibilidade que ele compartilha com um grupo mais restrito, com seu contexto social-histórico.

Dizer que nossa percepção é cultural-histórica é dizer que, em parte e segundo as modalidades a explorar, ela também se origina na instituição. Mas, instituição do quê? Como a cultura não instala em nós dispositivos mecânicos de transformação dos dados sensoriais, nem minicomputadores de elaboração desses dados diferentemente programados em Veneza e na Babilônia, essa instituição só pode concernir à própria representação, o modo comum do representar; ela é, portanto... instituição de esquemas e de figuras que tornam possível a representação como participável e o fazer coletivo. Esses esquemas devem, a cada vez, tornar possível a 'percepção' daquilo que, a cada vez, é colocado como 'coisa'; mas devem fazer muito mais, já que devem organizar a totalidade do social efetivo como aquilo que é, a cada vez, pensável. Em toda evidência, é impossível que essas organizações - das coisas, dos homens, dos atos, dos pensamentos - sejam separadas e independentes umas das outras; há coerência, solidariedade interna, inerência recíproca - que teremos que explorar - para cada sociedade da posição e da visão das 'coisas naturais', do estatuto dos homens, das regras e das referências do fazer e do dizer [...] (Id., p. 191).

Em outras palavras, para além da determinação natural, a sensibilidade é, a cada vez, socialmente instituída. Longe de mera recepção, o fenômeno da sensibilidade envolve, ele também, diferentes níveis de atividade do ser: a ativação da potencialidade natural é processo de instituição de um modo de ser adquirido, mas que nem por isso deixa de ser uma experiência individual - como a fenomenologia não cessou de enfatizar.

É quase um truísmo sublinhar o quanto, para a formação humana, parece indispensável identificar, no seio mesmo da atividade do sujeito, o processo pelo qual ele se constitui a cada vez como um modo de ser singular, constituindo seus modos específicos de sentir, de se deixar afetar, de conhecer, de refletir, de imaginar, de se autoalterar - que, no vocabulário aristotélico, são as hexeis.

A héxis é definida, em Categorias (8 b 26), como um estado, isto é, como algo de relativamente estável, por oposição à diáthesis, entendida como disposição frágil, pois susceptível de mudança. À primeira vista, portanto, a distinção entre héxis e diáthesis nos reconduziria à oposição entre a imobilidade e a mudança (cf. supra). E, de fato, o critério da permanência, ou da duração, parece ser essencial para o estabelecimento das duas formas. No entanto, essa distinção nem sempre é tão nítida, já que, como observamos,

[...] pode ocorrer que, por força do tempo, uma disposição se encontre entranhada na natureza, tornando-se impossível de extirpar, ou difícil de abalar. Neste caso, será chamada de estado (héxis) (ARISTÓTELES, Categorias, 9 A 1).

E, de fato, comenta Richard Bodeüs, a disposição (diáthesis) é um pouco como um estado (héxis) potencial, e o estado (héxis) como uma disposição (diáthesis) realizada. Ou ainda: a disposição é uma qualidade adquirida que se manifesta, ou não, em um estado permanente; já o estado deve forçosamente manifestar-se como uma disposição (BODEÜS, 2002, p. 134, n. 2).

Percebe-se aqui, novamente, a originalidade do pensamento de Aristóteles em relação à tradição em que se inscrevia: é que, longe de remeter ao paradigma imóvel das formas ideais, os conceitos de héxis e diáthesis nos obrigam a examinar, observa Rémi Brague em um judicioso artigo dedicado ao tema, a constituição interna e a temporalidade própria aos fenômenos considerados, que só se deixam medir pelo mundo próprio que cada vivente cria para si: esta temporalidade diz respeito à sua forma singular de estruturação, de se relacionar tudo que ele não é, de "incluir" tanto o dado natural que o constitui como o meio físico em que evolui. Afinal de contas, a "cons- 
tituição interna dos fenômenos" só existe como promoção de um

[...] mundo que somente o vivente pode 'possuir', no qual ele se situa e a cujas medidas busca corresponder - quando, por exemplo, ele se regula pelos movimentos do sol [...] (BRAGUE, 1980, p. 287).

Deste ponto de vista, a diáthesis é a forma a cada vez singular de o ser introduzir, ou dispor, em seu mundo próprio, a realidade que sobre ele age. Tal como o fenômeno da sensibilidade exemplifica, a disposição que acomete o ser revelaria sua condição de paciente, capaz de sofrer de forma passageira uma afecção que lhe impõe uma certa "ordem", ou "ritmo", ou "estrutura": um som, uma sensação de frio, uma cor. E se, como Aristóteles afirma, o exercício repetido resolve-se na aquisição de uma nova héxis, de um novo modo de ser, nem todas as disposições são chamadas a este tipo de permanência. A sensação fugidia serve, pois, de metáfora para dizer sobre a provisoriedade que também caracteriza a apreensão pelo vivente da realidade que o circunda.

Mas o artigo de Rémi Brague nos mostra que a provisoriedade da diáthesis indica igualmente o modo como o humano "apreende" também, na realidade, o que [ainda] não está lá: neste caso, o conceito muda totalmente de figura e passa a mostrar implicações que a educação não pode ignorar:

A disposição é a apreensão do real em sua possibilidade. Apreender o que é como possível, perceber no que é a vibração do que pode ser é apreender historicamente. A apreensão diatética é uma apreensão histórica (Id., p. 295).

Eis como a provisoriedade da diáthesis nos reconduz ao movimento de constituição dos modos de ser do humano, à luz do qual a nítida oposição atividade versus passividade se dissolve: pois, se tudo do que existe tem sua forma particular de sofrer a ação do outro (ARISTÓTELES, Física, I, 7, 17-22), isto é, de ser paciente, o que melhor define a "passividade" do composto humano é que ela é sempre, concomitantemente, atividade organizativa. Ora, a atividade que tem o humano como agente não deve, quanto a ela, ser caracterizada como um fazer (poíesis)?

[...] a passividade [do humano] é de uma espécie diferente. Ela não consiste em sofrer de uma forma qualquer, mas em ser disposto a. E se aquele que é afetado é caracterizado como aquele que é disposto a, é porque o que o afeta (o poiético) é como um lógos. A disposição é a afecção por um lógos. A alma é lógos porque sua passividade só permite que ela sofra [pela ação de um] lógos. Ela é, assim, autoafecção (Id., p. 301-302).

\section{PrÁXIS: A AÇÃo HUMANA EM ARISTóteleS}

O substantivo práxis não é senão um dos termos gregos para dizer a ação: em virtude, porém, do denso trabalho de conceptualização empreendido sobretudo na Ética a Nicômaco, no pensamento aristotélico seu uso esteve intimamente associado às finalidades mesmas da existência humana. E, desde então, este trabalho admirável

[...] tornou-se o modelo das "filosofias práticas" que têm como tema central a preocupação ética com a finalidade (télos) com o bem (agathon e todos os compostos em eu) e o valor ou excelência individual e coletivas (areté, tradicionalmente traduzida por virtude). Em certo momento [da história da filosofia], a "filosofia prática" se transformará em "filosofia da prática": esta promoção moderna é porém preparada pela consistência própria ao termo clássico de práxis (CASSIN, 2004, p. 988-989).

Mais recentemente, porém, buscando desviar a problemática questão dos valores, muitos estudos filosóficos, sobretudo de origem anglo-saxônia, passaram a adotar como ponto de partida o paradigma físico (isto é, natural), fazendo assim evoluir suas análises da ação humana dos casos mais elementares daquilo que pode, de forma mais genérica, ser definido como "movimento natural" (cf. NATALI, 2004). ${ }^{7}$ Ora, não obstante o estatuto concedido por Aristóteles ao estudo da natureza, que serve de solo para o conjunto de sua obra e que se constitui, como lembrava Jean-Louis Labarrière, quase um terço dos tratados aristotélicos (LABARRIÈRE, 2004, p. 13), esta posição vai frontalmente contra a herança teórica do filósofo. De Aristóteles deve-se dizer que é definitivamente o pensador da diferença entre o humano e o animal (LABARRIÈRE, 2005), assim como da distinção entre movimento físico e ação humana (NATALI, 2002; MOREL, 2002): mas todo o problema consiste no fato de que estas definições não são postuladas como ponto partida, mas - o que faz a grandeza e originalidade de seu pensamento - são continuamente arrancadas do solo conceitual em que aparecem confundidas. Assim, o próprio do humano é enunciado

[...] a partir de um vocabulário que não [lhes] é em nada reservado...: possuir a aistehsis, a sensação/percepção é, sem dúvida, o que define a animalidade (em relação aos viventes que são os vegetais, e não à humanidade). Decerto... somente o homem possui o lógos... porém... o lógos, que se entende melhor aqui como linguagem ou discurso do que como razão... não faz o homem sair do reino da aistehsis, mas lhe concede uma que apenas a ele é própria, a do bem e do mal, do justo e do injusto etc. (LABARRIÈRE, 2005 , p. 38). ${ }^{8}$ 
No que, então, se basear, a que conceitos recorrer para distinguir a ação humana do evento natural, ou do simples movimento físico? A resposta mais evidente insiste sobre a referência aristotélica a um objetivo, a uma finalidade: e, por mais custosa que a operação acabe por se tornar, ao colocar em cena a noção no mínimo polissêmica de télos, como imaginar sem grande dose de ingenuidade ou de hipocrisia que se possa fazer a economia desta noção, sobretudo para pensar a prática da formação humana?

No entanto, por si mesma esta resposta não é suficiente pois, na medida em que se pode legitimamente falar de objetivos tanto para os processos naturais quanto para a história humana, ela apenas posterga a questão mais árdua da diferenciação entre uma teleologia natural e uma teleologia humana. Além do mais, o que impediria de enquadrar aí, como correntemente se fez, a "ação" das máquinas? (DESCOMBES, 1995, p. 56).

No que se refere à ação humana, não há como evitar a questão dos valores: a crítica mais evidente e, ao mesmo tempo, mais percuciente das elaborações da chamada "filosofia analítica" vem de J. Habermas, que destaca as pesadas consequências da adoção do paradigma físico, incapaz de ver além do modelo de um ator isolado e de uma ação atomizada (HABERMAS, 1993, 89s). ${ }^{9}$ Toda a questão parece situar-se, então, em como fazer intervir a referência a um télos, a uma finalidade, sem projetar imediatamente a reflexão no terreno do idealismo: em seu estudo das "Ações e movimentos em Aristóteles" Carlo Natali pondera que a filosofia prática dos "continentais" peca, quanto a ela, justamente pelo travo idealista. Os exemplos abundam:

Por exemplo, Blondel, na virada do século XIX para o XX, sustenta que não é possível entender a ação humana sem partir da ideia do Puro Agir divino, entendido como "perfeita imanência no seio da transcendência absoluta" nas ações humanas e nos movimentos físicos, não se pode encontrá-la senão sob forma impura, mesclada de passividade. Também os neoidealistas italianos (Croce e Gentile) consideraram a ação humana como uma forma derivada e secundária, comparada ao Ato Puro (NATALI, 2002, p. 17).

Não foi, entretanto, apenas sob influência de um modelo ideal e metafísico que a ação humana se viu desvalorizada e reconduzida ao simples agir natural ou animal. Também a filosofia da prática do século XX elegeu um paradigma ideal, em face do qual todo o resto só pode aparecer como incompleto e insuficiente: é o caso da noção de trabalho, para o marxismo:

[...] o marxismo, em algumas de suas versões mais filosóficas, tomou o trabalho como paradigma e como caso emblemático a partir do qual se pode explicar a ação humana. Serve de exemplo a posição de Lukács, para quem o trabalho pode servir de modelo de compreensão para todas as outras atividades humanas, na medida em que seria forma ontologicamente originária. O sociólogo Alain Touraine partilha desta posição, fazendo da categoria trabalho uma categoria central de sua sociologia da ação (Id.).

Outras correntes filosóficas propõem ainda outros casos emblemáticos: a própria teoria de Habermas e Apel propõe a comunicação, ou antes o agir comunicativo como paradigma para todo tipo de ação. Passa-se assim, comenta Natali, "do estudo de todas as ações ao estudo da ação que é a mais ação entre todas" (Id.). Decerto o critério de referência para estas análises já não é mais o intangível metafísico: mas realiza-se ainda, de toda forma, a promoção do caso privilegiado ao status de norma única e monopolizadora dos sentidos da ação humana.

Contrariamente ao que propõe a filosofia analítica, a ontologia aristotélica parte da ação complexa, e não do movimento mais elementar para pensar a excepcionalidade humana. Foge-se, assim, do descritivismo, da tentação de "explicar" a ação humana, transformando-a em mecanismo, ou em simples consequência de causas previamente fixadas. A ação humana é complexa: ela pode ser elucidada por referência a seu sentido, ao que se pode denominar seu "fim". Reintroduz-se assim o espaço para a iniciativa, ali onde se havia pretendido instalar apenas o movimento mecânico de uma cadeia de causas e efeitos naturais.

Em contrapartida, a intricada teia conceitual em que se move a ontologia aristotélica da ação alerta-nos para o fato de que não é possível acomodar a complexidade da ação humana em um modelo de agir construído a partir de um paradigma único: escapa-se, portanto, das armadilhas da prescrição ao preço, é bem verdade, da redobrada atenção que exigem as sutilezas conceituais e, mesmo, as aparentes contradições do texto aristotélico.

Dissemos que a abordagem aristotélica não se interessa pela descrição minuciosa das características próprias da ação nem pela prescrição de um modelo de ação exemplar que sirva de critério universal para avaliação das ações. Mas isso não quer dizer, evidentemente, que a perspectiva de análise não seja a da ética. Pelo contrário: em Aristóteles o estudo da ação tem em vista a reflexão sobre a natureza do bem humano e da felicidade. E isso porque, para Aristóteles, a felicidade, ou a vida feliz, não é uma aquisição, o objeto de uma posse, mas uma atividade prática que define e atualiza a cada momento o caráter do agente, ele próprio definido pelas escolhas realizadas, pelo tipo de vida que ele decide levar (ARISTÓTELES, Ética a Eudemo, I, 4, 1215 a 15-19). A felicidade é definida, na Ética a Eudemo, como a atividade (enérgeia) de uma vida conforme à virtude (Id., 1219 a 38-39). 
É bem verdade que Aristóteles apoia frequentemente suas teses em exemplos - que não funcionam, no entanto, como critérios gerais nem muito menos como elementos de definição: estas ocorrências abundam na Ética a Nicômaco e também na Política. Decerto, estes exemplos não deixam de representar também o "melhor caso": no entanto, eles servem como principio de interpretação para diferentes outros tipos de casos, cujas condições aparecem de forma menos clara: é que, para Aristóteles, não se deve limitar a reflexão a um estudo parcial de seu próprio argumento, mas levá-lo até seus limites de inteligibilidade. Seu exame, pois, "do melhor caso" não invalida a consideração dos demais, mas, complementado pela referência ao "mais comum", evidencia constantemente que "é impossível dar uma regra que valha para todos os casos" (ARISTÓTELES, Política., IV, 1, 1289 a 22-25).

Assim, diferentemente do caráter normativo que a ética recebeu na Modernidade - por influência, sobretudo, do kantismo - e para não abdicar da complexidade própria ao agir humano, a ética aristotélica recorre a um procedimento muito comum na Antiguidade: o exemplo (parádeigma). A ação humana nunca é igual - ela não está submetida ao tipo de determinação precisa e válida para todos os casos (akribes) que serve para os fenômenos naturais, mas depende, justamente, de iniciativa:

As ciências rigorosas e que se bastam a elas próprias não dão lugar à deliberação. [...] Mas o que podemos fazer por nós mesmos pode não ser sempre o mesmo, e é isto o objeto de nossa deliberação [...] A deliberação tem lugar em coisas que, se produzindo com frequência, permanecem incertas quanto ao resultado, isto é, coisas que comportam o indeterminado [...] (ARISTOTELES, Etica a Nicômaco, III, 51112 b $1-10)$.

Aristóteles introduz aí um critério que não está presente na ética de Platão, e que se refere à probabilidade; afinal, como o pensamento antigo tantas vezes afirmara, no mundo de incertezas em que vive o humano, não há como achar uma lei que garanta o resultado final. $\mathrm{Na}$ tradição grega, "mesmo os filósofos mais otimistas quanto às possibilidades da razão reconhecem a dificuldade de encontrar uma regra para a ação humana" (NATALI, 2002, p. 16).

Uma primeira resposta a esta dificuldade é fornecida pela teoria do justo meio que, de origem médica, é desenvolvida, como se sabe, por Platão e Aristóteles: longe de partir de uma regra geral, porém, em Aristóteles ela consiste em analisar os casos particulares, eliminando metodicamente as escolhas que se mostram inadequadas. Assim, comenta Natali, "concentra-se progressivamente o domínio da incerteza sobre um segmento de possibilidade sempre mais restrito e sempre mais afastado dos erros opostos [...]" (Id.).

Mas, via de regra, Aristóteles lança mão, como dissemos, de outro procedimento tradicional, que é o exemplo. Aí, também, não se trata de encontrar certezas ou garantias absolutas, mas em inferir da experiência do passado elementos que permitam definir uma linha de ação (ARISTÓTELES, Retórica, I, 9, 1368 a 29-31). Assim, tudo o que se pode depreender do agir humano são coisas que "acontecem mais frequentemente"; este conhecimento é, no entanto, fundamental para que se possa falar em deliberação. E, de fato, se o agir humano estivesse inteiramente submetido a determinações naturais (a condições necessárias) ou se, ao contrário, não se pudesse dele retirar qualquer constância ou regularidade (condições acidentais), não haveria sentido em se falar de ética. Mas o domínio do agir humano, a ética, não é o de uma ciência rigorosa. A "ciência" do agir humano é estocástica: tratando com probabilidades, ela tem certo potencial demonstrativo, mas admite exceções.

O uso do parádeigma em Aristóteles está associado a esta característica do agir humano: a ausência de necessidade em nossas ações torna útil o recurso a exemplos, assim como a relativa constância dos comportamentos humanos torna provável a repetição dos mesmos comportamentos em circunstâncias análogas [...] Por isto, a relativa constância das ações humanas é a base antropológica sobre a qual Aristóteles pode construir sua interpretação dos exemplos [...] (NATALI, 2004, p. 20).

Esta constância tem menos raízes nas leis psicológicas que, como Castoriadis não cessou de relembrar, Aristóteles foi o primeiro a descobrir (CASTORIADIS, 1987, p. 351; ARISTÓTELES, De Memoria et Reminiscentia, 441 b 18-20), do que no fato de que o humano é capaz, como acabamos de ver, de instituir suas próprias hexeis, seus modos de ser. Aristóteles dizia que o sujeito ético age de forma mais constante do que o indivíduo que não se determina a ele próprio por leis do bom agir: pois, neste último caso, ao invés de serem atenuadas, as incertezas da existência humana se veriam aprofundadas, o acaso dos acontecimentos presidindo a comportamentos sempre circunstanciais (ARISTÓTELES, Etica a Nicômaco, III, 5 1112 b 1-10). Mas é claro que uma previsibilidade sempre mais precisa e estatística emerge ali onde a alienação substitui a prática da deliberação (ARENDT, 1987, p. 53).

Longe, portanto, de fixar um critério específico que deve servir de medida para todo tipo de comportamentos humanos, o parádeigma permite preservar a complexidade de cada caso apresentado, do qual se podem tirar linhas de ação que conservam, também elas, um forte grau de incerteza - não só porque não derivam de normas 
universalmente válidas, como porque se destinam a uma situação prática que só pode ser aproximativamente dada por homóloga ao caso estudado. Não por acaso, o principal modelo fornecido pela Ética a Nicômaco remete não para um conceito abstrato de virtude, mas para a figura do sujeito da justiça, o justo - o spoudaîos (PETIT, 2002, p. 71).

[...] a virtude é uma disposição adquirida (héxis proairetikè), consistindo no justo meio (mesóteti) determinado por uma regra (lógos) semelhante àquela que um homem prudente (phrónimos) estabeleceria (ARISTÓTELES, Ética a Nicômaco, II, 6, 1107 a 2).

Para os objetivos que são os nossos, o procedimento metodológico de Aristóteles, afastando-nos das soluções de facilidade que consistiriam em calcar nosso estudo da ação humana no padrão claro e distinto do movimento físico ou no conforto aparentemente axiomático do modelo ideal, nos reconduz à complexidade. Por onde, então, começar a abordá-la?

Uma das principais vias abertas pelo filósofo grego é sem dúvida aquela que é demarcada pelas noções de poíesis e de práxis: percorrendo-a, convencemo-nos definitivamente de que se tem aí um percurso obrigatório para a reflexão sobre a formação humana.

Na Ética a Nicômaco, Aristóteles parece distinguir dois tipos de atividade humana: a poíesis ou produção, que a princípio poderia ser aproximada do acontecimento natural, e a práxis ou ação, que escapa totalmente ao modelo físico. E como, em sua acepção mais geral, o poiein indica simplesmente o fato de se produzir um efeito, deve-se observar que a poeisis recobre o sentido que até aqui vimos dando ao termo "atividade". É possível, porém, identificar no texto aristotélico pelo menos três formas de poíesis, de acordo com os diferentes "efeitos" produzidos: fabricação de um novo objeto, produção de um novo estado para um ente já existente, ou realização do que se deve denominar de ação ética (NATALI, 2002, p. 23-26).

Entendida como fabricação de um novo ente (diríamos, de um "produto", um objeto material ou não), a poíesis é movimento que tende para e que se esgota nesta produção que marca também seu encerramento. Nesta primeira ocorrência, ela define uma atividade imersa nas exigências da funcionalidade que regula $o$ acontecimento natural e que, desse modo, se caracteriza pela precariedade: sua realização sela seu fim. Na segunda ocorrência, porém, a poíesis ganha um sentido mais complexo, definindo agora um espectro que vai da criação de novas disposições (diáthesis), como a que o orador produz em sua plateia, até a formação de novos modos de ser (hexeis) - tal como, justamente, pretende suscitar a educação.
Não é difícil perceber que o contínuo que leva da primeira à terceira acepção da poeisis é o mesmo que separa, segundo Aristóteles, o simples movimento físico (kinesis) da iniciativa ética a que reservaremos o conceito de práxis. A análise permite contudo a Aristóteles sublinhar um aspecto fundamental da questão: é que o humano, se fazendo origem de movimentos não necessários, no sentido em que não são previamente determinados pela natureza, é capaz de ações que não estão, elas próprias, reguladas por antecipação, podendo ocorrer de uma maneira ou de outra, ou simplesmente não ocorrer (ARISTÓTELES, Etica a Eudemo, I, 2, 1214 b 17-25; II, 6, 1222 a 15-30). Em outras palavras, não estando (inteiramente) submetida, nem ao acaso, nem a leis invariáveis, a ação humana é livre, e depende de deliberação (ARISTÓTELES, Ética a Nicômaco, VI, 3, 1140 a 25 b 5).

Em outro texto, a diferença entre ação e movimento é estabelecida a partir do ponto de vista da finalidade e da natureza da atividade realizada: assim, na ação (práxis), “o fim, que é o produto (ergon) da ação [...] coincide com a própria ação (enérgeia)", enquanto nos movimentos naturais o fim é a produção de um objeto ou de um estado de coisas que são exteriores à ação (ergon) (ARISTÓTELES, Metafísica, Q, 6, 1048 a 25-1048 b 17).

A ação que contém em si sua finalidade (práxis teleia) é designada, no vocabulário aristotélico, como ação perfeita, inteiramente realizada: não há, neste caso, interregno de tempo, processo a ser vencido em vista de um produto que fixa também a cessação do movimento.

Tudo estaria dito, e a oposição entre a práxis e o movimento físico rigorosamente afirmada, como propõe Metafísica Q, VI, 1048 b 28 - 1048 b 35, se, na Ética a Eudemo, a prática não estivesse designada como um (tipo de) movimento (Id.): e como, em geral, as aporias não sabem bem aos comentaristas, muitos foram, entre antigos e modernos, que buscaram resolver a questão afirmando que, para Aristóteles, a "verdadeira ação" não estava retratada pela Ética, mas figurava apenas na atividade divina - que, como tal, não poderia estar sujeita a limites temporais ou a mudanças, sendo portanto concebida como permanência, como imobilidade.

Estaria, dessa forma, a atividade humana reduzida ao fazer, à poíesis? A solução, como se pode imaginar, tinha tudo para agradar não apenas à tradição cristã - que podia assim tornar toda iniciativa humana uma sombra deficiente e empobrecida da "práxis divina" - quanto aos materialismos modernos - para os quais, de fato, a subsunção da práxis à poíesis foi, mais do que uma concessão, uma petição de conveniência.

Mas esta resposta dificilmente conviria a quem interessa o exame da singularidade do pensamento aristotélico, que consiste em fornecer à iniciativa humana 
- esta mesma que fora capaz de criar a pólis democrática que o filósofo tanto admirava - toda a sua dignidade.

Assim, para entender de forma adequada a práxis humana, tal como Aristóteles a concebe, será preciso manter à distância tanto o parâmetro puramente físico, quanto o ideal divino. Esta era a interpretação de H. Arendt, expressa em toda a sua reflexão sobre as singularidades que definem a Condição humana: "só a ação é prerrogativa exclusiva do homem; nem um animal nem um deus é capaz de ação [...]" (Id., ibid.). E esta é também a posição de ilustres estudiosos da obra aristotélica - como Carlo Natali, cujos comentários vimos aqui seguindo. Assim, a prática humana, diz ele, mesmo em sua forma mais elevada - que seria para Aristóteles identificada ao pensamento ou à atividade noética comportaria movimento físico, diferenciando-se deste modo da atividade pura das divindades imóveis. A ação humana tem características que faltam à atividade divina - como o justo meio e a deliberação. Por isso, conclui o autor,

[...] mesmo que a ação humana seja um certo tipo de atividade, enérgeia, ela não é idêntica a toda atividade, e tem características próprias que a diferenciam das demais. Ela tem a mesma natureza complexa e intermediária que o humano no cosmos de Aristóteles (NATALI, 2004, p. 10).

Mas é exatamente porque a ação humana não é simples, mas compósita, que a oposição entre práxis e poíesis, até certo ponto tão esclarecedora, ${ }^{10}$ tampouco ela se mostra suficiente para elucidar-lhe a singularidade: e, para demonstrá-lo, seria preciso apenas, como Aristóteles nos ensinou, passar à análise da situação encarnada, do caso particular: o que, na prática da formação humana, a oposição entre práxis e poeisis dá a ver, e o que ela esconde?

É no capítulo 4 do livro VI da Ética a Nicômaco que, após serem incluídas no rol das "coisas que podem ser diferentes do que são", práxis e poíesis são distinguidas:

As coisas que podem ser outras do que são compreendem, tanto as coisas que se fabricam (poieton) quanto as ações que se realizam (prakton)... Com efeito, a ação (práxis) não é uma produção (poiêsis) nem uma produção, ação (ARISTÓTELES, Ética a Nicômaco, VI, 4, 1140 a 1-5).

Como esta diferença não é explicitada, costumou-se associar esta passagem àquela que, no início da obra (Id., I, 1, 1094 a 1-5) distingue a situação em que o fim (télos) coincide com a atividade (enérgeia) e aquela em que o fim é uma obra (ergon). Assim, a atividade (enérgeia) corresponderia a um modo de presença do télos em que ele não marca a cessação da atividade mas, ao contrário, sua permanência. ${ }^{11}$ Por outro lado, à poíesis corresponderia um produto para o qual a atividade tendeu, que somente ele dá sentido à atividade.

Não deveria a formação humana ser compreendida como poiética, na medida em que a ela devem corresponder finalidades objetiváveis e exteriores à atividade, objetivos comuns e públicos, capazes de fornecer parâmetros para o acompanhamento, a prestação de contas e a avaliação do trabalho realizado? Ainda que disto pareça depender o caráter democrático da atividade, é preciso convir que não faltaram, na história da educação, aqueles que proclamaram que o êxito do processo educativo dependia quase que inteiramente da fixação de "objetivos instrumentais", isso é, que anunciavam a falaciosa possibilidade de se traduzirem em uma lista bem acertada de metas objetivas e facilmente observáveis o conjunto indefinido de finalidades da autocriação humana.

Deveria, ao contrário, a formação humana ser arrolada entre as atividades para as quais não se podem designar fins objetiváveis, que estas atividades não visam nenhuma finalidade além de seu próprio exercício? Não se concluindo pela realização de nenhum "produto", não tendo uma finalidade exterior a elas, diz-se destas atividades que têm fim em si mesmas, ou que são seu próprio fim, que elas são práticas. As atividades práticas não se concluem forçosamente pela fabricação de um "produto": isso torna impossível a fixação de um momento preciso e definitivo para seu encerramento, tanto quanto impossibilita qualquer tentativa de se proceder à sua "avaliação objetiva". E, de fato, como fixar um fim para a autoformação, como separá-la artificialmente da própria existência? Como avaliar objetivamente uma ação que não tem um "resultado" ou um "efeito" preciso, mas se refere ao que cada humano é e faz de si?

Examinando os limites da distinção entre práxis e poiêsis, Cornelius Castoriadis identificou três casos em que ela não parece adequada, todos eles relativos a atividades de formação humana: a política, a educação e a psicanálise. (CASTORIADIS, 1982, p. 40-41). Por um lado, se sucessivas "objetivações" são necessárias, é porque o humano não se autocria isoladamente, mas sempre no contexto de uma sociedade; mas, por outro lado, estas definições têm aqui um caráter não somente limitado, que não expressa a complexidade do processo, como provisório, já que elas forçosamente se modificam.

Assim, não será preciso seguir as polêmicas entre os comentaristas para convir que, no que respeita à formação humana, ao menos quando ela é entendida como processo de auto-alteração, a oposição entre práxis e poiêsis, francamente inadequada, tem ao menos o mérito de obrigar nosso pensamento a ir adiante: foi o que fez Castoriadis, propondo para a política, a educação e a psicanálise a noção de "atividades prático-poiéticas": 
nelas, a autonomia se constitui, ao mesmo tempo, no fim a ser buscado e na própria atividade. Em outras palavras, nas diferentes dimensões em que se dá a formação humana, o processo e o produto, os meios e os fins se confundem, e não já há como distingui-los inteiramente.

\section{O QUE VEM DEPOIS...}

É evidente que as reflexões aqui registradas não tiveram nem poderiam ter por finalidade levar à produção de novas e acabadas certezas teóricas, tampouco de conclusões pragmáticas de pronto uso nas lides educacionais; esperamos, contudo, que possam servir para abrir uma interrogação sobre as representações que vêm, consciente ou inconscientemente, definindo nossas formas de lidar com o humano - professor ou aluno - e de conceber as relações entre os dois. Com base em textos de reconhecidos especialistas, pretendemos demonstrar como a filosofia aristotélica nos ajuda a integrar a noção de movimento, tão claramente ligada à ideia de autoalteração e, assim, à própria possibilidade de prática educativa, à nossa concepção do humano e de seu desenvolvimento; pretendemos, ainda, ressaltar de que forma esta filosofia nos habilita a pensar, para além do impasse platônico, "como é possível adquirir aquilo que não se tem" (VALLE, 2002, p. 47-126). E se pretendemos, em particular, demonstrar que Aristóteles foi muito mais e outra coisa além do filósofo naturalista que dividiu a existência do vivente entre "potência" e "ato", é porque esta confirmação não afeta apenas a memória do Estagirita, mas reafirma, para nós, uma antiga exigência: a de que possamos repensar a educação para além das fáceis e enganosas oposições entre natureza e cultura, ato e potência, inato e adquirido, investindo nosso pensamento na capacidade humana de criar o novo, de se autocriar, de realizar-se realizando, enfim, sua autoformação.

\section{REFERÊNCIAS}

ARENDT, Hannah. A condição humana. Rio de Janeiro: Forense Universitária, 1987.

ARISTÓTELES. Categorias, 9 a 1. [Catégories. Trad. Richard Bodeüs. Paris: Belles Lettres, 2002].

ARISTÓTELES. De l'âme [De Anima.. Trad. Richard Bodeüs. Paris: Flammarion, 1993; Jean Tricot. Paris: Vrin, 1988].

ARISTÓTELES. De memoria et reminiscentia [Parva Naturalia], 441 b 18-20 [De la mémoire et de la réminiscence, Petits traités d'histoire naturelle. Trad. René Mugnier. Paris: Belles Lettres, 2002].

ARISTÓTELES. Ética a Eudemo [Éthique à Eudème. Trad. Vianney Décarie. Paris: Vrin, 1987].

ARISTÓTELES. Ética a Nicômaco [Éthique à Nicomaque. Trad. Richard Bodeüs. Paris: Flammarion, 2004].
ARISTÓTELES. Metafísica [Métaphysique. Trad. Jean Tricot. Paris: Vrin, 2000].

ARISTÓTELES. Physique [Física]. Trad. L. Couloubaritsis. Paris: Vrin, 1991; Trad. Henri Carteron. Paris: Belles Lettres, 1990.

ARISTÓTELES. Política [Politique. Trad. Jean Aubonnet. Paris: Vrin, 1996].

ARISTÓTELES. Retórica [Rhétorique. Trad. M. Dufour. Paris: Belles Lettres, 2003].

BESNIER, Bernard Besnier. A distinção entre práxis e poiêsis em Aristóteles. Analytica, v. 1, n. 3, 2006.

BODEÜS, Richard. Catégories. Introduction. Paris: Belles Lettres, 2002. p. I-CCXVIII.

BRAGUE, Rémi. De la disposition chez Aristote. In: AUBENQUE, Pierre. Concepts et catégories dans la pensée antique. Paris: Vrin, 1980.

BRAGUE, Rémi. Aristote et la question du monde. Paris: PUF, 1988.

CASSIN, Barbara (Org.). Vocabulaire européen des philosophies. Paris: Seuil/Le Robert, 2004.

CASTORIADIS, Cornelius. A instituição imaginária da sociedade. Rio de Janeiro: Paz e Terra, 1982.

CASTORIADIS, Cornelius. Encruzilhadas do labirinto. Rio de Janeiro: Paz e Terra, 1982.

CASTORIADIS, Cornelius. Encruzilhadas do labirinto II: Domínios do homem. Rio de Janeiro: Paz e Terra, 1987.

CASTORIADIS, Cornelius. Encruzilhadas do labirinto V: Feito e a ser feito. Rio de Janeiro: DPA, 2000.

DELEUZE, Gilles, Différence et répétition. Paris: PUF, 1989. DESCOMBES, Vicent. La denrée mentale. Paris: Minuit, 1995.

FOUCAULT, Michel.Sur la nature humaine. Bruxelas: Aden Belgique, 2005.

FOUCAULT, Michel. Surveiller et punir. Naissance de la prison Paris: Gallimard, 1978.

GUMBRECHT, Hans. A produção da presença: o que o sentido não consegue transmitir. Rio de Janeiro: Contraponto/ PUC-Rio, 2010.

HABERMAS, Jurgen, Teoria dell'agire communicativo. Bolonha: Il Mulino, 1986, p. 379-456, apud NATALI, Carlo. Actions et mouvements chez Aristote. Philosophie, n. 73, mar. 2002.

HABERMAS, Jurgen. Consciência moral e agir comunicativo. Rio de Janeiro: Tempo Brasileiro, 1983.

HUMMEL, Charles. Aristote et l'éducation. In: SINACEUR, M. A.; AUBENQUE, Pierre. Aristote aujourd'hui. Paris: Unesco, 1998. p. 136-167.

LABARRIÈRE, Jean-Louis. La condition animale: études sur Aristote et les stoïciens. Louvain-la Neuve: Peeters, 2005.

LOMBARD, Jean. Aristote. Politique et éducation. Paris: Harmattan, 1994.

LOMBARD, Jean. Langage, vie politique et mouvement des animaux: études aristotéliciennes. Paris: Vrin, 2004. 
MARROU, J.-I. Histoire de l'éducation dans l'Antiquité. v. 1 - Le monde grec. Paris: Seuil, 1948.

MOREL, Pierre-Marie. Aristote. Une philosophie de l'activité. Paris: Flammarion, 2003.

MOREL, Pierre-Marie. Action humaine et action naturelle chez Aristote. Philosophie, n. 73, mar. 2002.

NATALI, Carlo. Actions et mouvements chez Aristote. Philosophie, n. 73, mar. 2002.

NATALI, Carlo. L'action efficace: études sur la philosophie de l'action d'Aristote. Louvain-la-Neuve: Peters, 2004.

PETIT, Alain. Eupraxia, fin inconditionnelle. Philosophie, n. 73. Paris: Minuit, 2002.

PLATÃO, Menon [Mênon]. Trad. Louis Bodin. Paris: Belles Lettres, 1942.

RODRIGO, Pierre. Aristote. Une philosophie pratique: práxis, politique et bonheur. Paris: Vrin, 2006.

VALLE, Lílian do. Os enigmas da educação: a paidéia democrática entre Platão e Castoriadis. Belo Horizonte: Autêntica, 2002.

\section{NoTAS}

1 As citações das obras dos filósofos gregos são feitas de acordo com normas universalmente aceitas e seguidas em todas as línguas, mencionandose as páginas e colunas que constam das edições clássicas. Assim, por exemplo, ARISTÓTELES, Física, II, 192 b 8, identifica as referências que permitirão, em qualquer tradução que se escolha, encontrar a passagem mencionada no livro II da Física.

2 A capacidade de se deixar afetar é uma dýnamis que os seres inanimados também possuem: p. ex., Aristóteles, Metafísica D, 12, 1019 b 14. [Métaphysique. trad. Jean Tricot. Paris: Vrin, 2000.]

3 O modelo aqui não é, evidentemente, o sujeito isolado. Pierre Rodrigo (2006, p. 126) opõe a insistência aristotélica em caracterizar como particular a ciência a cada vez adquirida ao movimento cartesiano: “[...] o 'método' e a mathésis cartesianas supõem o abandono radical da héxisapodeiktiké aristotélica em proveito de um saber universal em sua forma - em outras palavras, em proveito de um saber que não se modela mais sobre nenhuma "ciência particular", mas que simplesmente amplia "a luz natural de [nossa] razão (Descartes, Regra I) Deste ponto de vista, a dinâmica da héxisconstituiu-se na exata antítese metafísica da ordem metódica cartesiana."
4 A referência é ao De Anima, III, 8, 432 2-9.

5 Aristóteles distingue uma única potencialidade que é separável do corpo, ao menos sob um certo aspecto - a saber, o noûs.

6 Diz Morel (2003, p. 272): "De forma geral, enquanto [a faculdade nutritiva-vegetativa] é comum a todos os viventes, a sensação e, com ela, a imaginação não pertencem senão ao animal. O intelecto é o próprio do animal humano." Contudo, para Castoriadis, não é tanto a capacidade racional (lógica) mas a imaginação que, liberada da servidão da pura funcionalidade, faz ser o pensamento e a sensibilidade que garantem a singularidade humana entre as espécies. (Cf., entre outras passagens, CASTORIADIS, 1987 , p. 272.)

7 Carlo Natali (2002) enumera alguns exemplos de que partem os estudos contemporâneos da ação: levantar o braço (Arthur Danto), cair (White), bocejar (John L. Austin), entrar em um restaurante, fazer uma careta de dor (P. Brand Blanshard), estender o braço para abrir uma porta (Carl Ginet).

8 A referência é à Política, $\mathrm{I}, 1$.

9 Carlo Natali (2002, p. 16) cita expressamente a Teoria dell'agire communicativo.

${ }^{10}$ Para alguns comentaristas, contrariamente ao que disse a tradição, não é possível ler, no conjunto da obra aristotélica, uma distinção entre práxis e poeisis. Esta interpretação não coloca em questão, no entanto, as implicações que se tiram aqui da dupla de conceitos (Cf. BESNIER, 2006).

${ }^{11} \mathrm{Na}$ enérgeia dar-se-ia a integração da ação (práxis) e do télos - coincidência que pode, segundo Rémi Brague, ser lida em duas direções: a realização plenamente acabada coincide com o presente, o fim está lá, "atingido" desde o início da ação, não há progressão, mas imediatez; a outra possibilidade é que o presente coincida com a plena realização, que seja a ação desenvolvida o próprio fim. Num caso, o passado é sempre retomado e jamais superado; no outro, é o presente que jamais se torna passado. É esta qualidade do presente que, para Brague, marca na enérgeia o encontro da práxis com seu télos: "Estar em vida significa levar uma certa vida, e não simplesmente se achar em vida. "Estar" não significa, neste caso, "encontrar-se", tal como uma coisa "se encontra ali", mas implica um processo interno. A vida, porque ela é uma enérgeia, participa da característica da enérgeia ... ela não é... um simples "encontrar-se ali", mas um "advir". Este advir, este processo, não é tanto a maneira como eu conduzo minha vida, escolhendo a cada instante o que será meu advir senão um advir já interior a meu presente. Não posso estar em vida neste momento sem ser a realização (aboutissement) de um passado que possuo como meu. Este passado, porque é o resultado de minha vida presente, não está revoluto." (BRAGUE, 1988, p. 479-480).

Artigo recebido em outubro 2013.

Aprovado em abril 2014. 